\title{
Política na Capela: eleição municipal no Vale do Paraíba Paulista
}

\author{
Carlos Eduardo Pinto Procópio ${ }^{1}$ \\ Ana Keila Mosca Pinezi ${ }^{2}$ \\ Gilson Nascimento de Oliveira ${ }^{1}$ \\ ${ }^{1}$ Instituto Federal de São Paulo, São Paulo, SP, Brasil \\ ${ }^{2}$ Universidade Federal do Triângulo Mineiro, Uberaba, MG, Brasil
}

\section{Resumo}

Este texto pretende analisar as eleições municipais de 2016 na cidade paulista de Aparecida, centro de uma das maiores devoções marianas no Brasil, enfatizando as disputas entre atores políticos e religiosos a partir das demandas materiais e simbólicas da cidade. No contexto desse pleito, os postulantes à prefeitura e os administradores religiosos do Santuário Nacional se concentraram no levantamento de problemas a serem sanados e nas soluções necessárias para o atendimento dos moradores locais e dos romeiros. Os atores em disputa colocaram suas perspectivas sobre a cidade tendo como ponto de partida a condição de terra santa e a função religiosa que, como tal, deveria executar. Na medida em que o processo eleitoral se desdobrava, os limites entre atores políticos e religiosos eram deslocados, confrontando os sentidos e imagens da cidade, tomados e endereçados a partir do interesse das partes em disputa.

Palavras-chave: Aparecida. Eleições Municipais. Arena Pública. Religião. Política.

\section{Policy on the Capela: elections in the Paraíba Valley}

\begin{abstract}
This paper analyzes the elections of 2016 in Aparecida, emphasizing the disputes between political and religious actors from the material and symbolic demands of the city. In this election, the candidates for mayor and religious administrators of the Santuário Nacional sought to list problems that affected local residents and pilgrims. Their arguments mentioned the condition of holy land and the religious function that the city should perform. In this context, the boundaries between political and religious actors were displaced, confronting the senses and images of the city, taken and addressed from the interests of the disputing parties.
\end{abstract}

Keywords: Aparecida. Elections. Public Arena. Religion. Policy. 


\section{Introdução}

$\mathrm{A}$ cidade de Aparecida, localizada no Vale do Paraíba Paulista, é conhecida por ser a Capital Mariana do Brasil, recebendo nos finais de semana e feriados quase 13 milhões de peregrinos anualmente. Em torno do Santuário Nacional, seja o antigo ou o novo, desenvolve-se ampla atividade comercial, desde hotéis e pousadas para atender aos romeiros, passando por bares e restaurantes, até lojistas e ambulantes, que tiram do turismo religioso sua fonte de renda. Contudo, nos dias em que a presença de peregrinos é muito rala, a cidade ganha um contorno bastante diferente. O movimento das ruas ganha uma toada mais pacata, e os quase 40 mil habitantes de Aparecida se veem, por alguns dias, vivendo em uma cidade com seus ares interioranos.

Esse centro sagrado, para usar um termo utilizado por Turner (1973), não só vai desenvolver e administrar os aspectos religiosos da vida local, mas também os efeitos dos aspectos econômicos e políticos derivados da função religiosa original, o que acaba incidindo sobre a maneira como Aparecida será pensada, organizada e disputada. Isso se acirra quando a eleição municipal que vai escolher prefeito e vereadores é realizada, escancarando as disputas que aproximam e distanciam atores seculares e religiosos. Os primeiros, distribuídos por inúmeros segmentos políticos que vão ganhar a forma de partidos e coligações, registrando e patrocinando nomes para buscar a adesão dos cidadãos aptos a votar. Os segundos, organizados dentro de uma corporação chamada de Igreja Católica, que vai ser pauta e vai pautar quase que toda a agenda e plataforma daqueles que miram as vagas representativas do poder público municipal. Ao se colocaram em face um do outro, se observam em cena discursos trípticos (MONTERO; SILVA; SALES, 2018), colocando em evidência a maneira como atores seculares e religiosos fazem arenas públicas tanto quanto se fazem nelas.

Em Aparecida, os dilemas relacionados à conformação da cidade como a capital mariana do Brasil e os problemas relacionados a seu desenvolvimento são elementos que fomentam as controvérsias em torno da disputa pelo poder municipal, especialmente no pleito de 2016, foco de nossa pesquisa. Às vésperas de comemorar os 300 anos do descobrimento da imagem por pescadores no rio que corta a cidade e sob críticas de que a prefeitura não havia preparado a cidade para o tamanho do evento que se realizaria, seis candidatos lançaram suas candidaturas à prefeitura pela preferência dos 27 mil munícipes habilitados a votar, movimentando diuturnamente a cidade entre os meses de agosto e setembro. Nesse cenário, a disputa pela prefeitura forçou os candidatos a dialogarem com os usos e sentidos religiosos da cidade, sofrendo pressão não só das demandas da 
população local, mas também de grupos de interesse que reivindicam coisas em nome dessa população, especialmente os gestores do Santuário Nacional.

\section{Aparecida: cotidiano, religião e política}

As eleições de 2016 em Aparecida podem ser pensadas a partir de alguns aspectos que atravessavam o imaginário da cidade. Neste ano em que o pleito eleitoral era realizado, Aparecida estava às vésperas de completar 300 anos do descobrimento da imagem de Nossa Senhora Aparecida. Desse modo, seus habitantes eram confrontados com temas projetados desde as esferas da religião e da política. O Santuário' ${ }^{1}$ que administra os aspectos religiosos da cidade, organizava-se para celebrar o acontecimento, estimulando os fiéis, vindos de várias partes do Brasil, a se empenharem para celebrar o momento com pujança, mas também procurando produzir reflexões veiculadas na sua rádio, televisão, livros e materiais diversos sobre a importância do descobrimento da imagem e a sua importância para a fé religiosa católica na região e no país. Ao mesmo tempo, é do próprio Santuário que vêm as pressões para que a administração municipal se empenhe em fazer sua parte, organizando a cidade e melhorando aspectos de mobilidade urbana e atendimento ao romeiro para que a celebração do terceiro centenário da Imagem da Padroeira pudesse ser gozada com júbilo por todos aqueles que visitariam a cidade em 2017.

Para o Santuário, a cidade apresentava problemas de diversas ordens e que afetavam a recepção de romeiros vindos de várias partes do país. O fato de Aparecida receber nos finais de semana e feriados uma população que, às vezes, chega a cinco vezes seu tamanho cotidiano fazia com que o Santuário reclamasse da ineficácia do atendimento na área da saúde, na falta de organização do trânsito nos dias de movimento pedestre e motorizado mais intenso, dos problemas de segurança e da qualidade de atendimento feita por hotéis, pousadas e restaurantes da cidade, além do problema da feira livre que se desenvolve aos pés da Basílica Nova, que, apesar de atrativo para os romeiros, seria um agravante em termos de atendimento e segurança. Em 2016, parecia ser lugar comum a visão de que a administração da cidade pouco estava fazendo para celebrar os três séculos do aparecimento da Imagem. Apesar de ser uma demanda vinda do Santuário, esses problemas não eram alheios aos cidadãos locais, que, em muitas ocasiões, reclamavam da maneira como a cidade estava sendo administrada.

Em relação à política, esses elementos administrativos e de infraestrutura, que tencionavam o cotidiano do município, atrelavam-se à questão da história política recente da cidade. O pleito anterior, em 2012, foi marcado pela vitória expressiva de um político local emblemático, Zé Louquinho, que teve sua candidatura impugnada pela Lei Ficha Limpa e acabou não assumindo a administração local, que se manteve na mão do então prefeito Márcio Siqueira, segundo colocado no pleito de 2012. Este acabou sendo afastado pela justiça, acusado de improbidade administrativa por pelo menos

O uso da expressão Santuário é ambivalente no contexto aparecidense. Pode fazer referência ao templo consagrado nos anos de 1980 pelo Papa João Paulo II e é também chamado de Basílica ou Basílica Nova. O Santuário também é utilizado como substantivo para a gestão religiosa da cidade, que congrega toda a burocracia que administra o templo e suas atividades em geral. É nesta última acepção que vamos utilizar ao longo deste texto, tal como era tomado no contexto das eleições de 2016. 
quatro vezes, levando seu vice, Sargento Ernaldo, a assumir a prefeitura nessas ocasiões. O maior período de afastamento começou a agosto de 2015, durando oito meses. Márcio foi reconduzido definitivamente ao cargo pelo Supremo Tribunal Federal em abril de 2016, mas a política da cidade já se encontrava com suas veias abertas. Os grupos políticos locais alimentavam controvérsias sobre as condições do prefeito de se manter em seu cargo, disseminando críticas ao seu mandato, estendendo-as a seu vice. Este, por sua vez, procurava marcar os êxitos da sua ação como administrador temporário do município, deslocando as críticas dos seus opositores. Ao chegar às eleições, Márcio Siqueira era letra morta, cujo capital político, se algum ainda lhe restava, não foi buscado por ninguém. Novos nomes vão despontar como portadores de capital político deslocados do eixo de políticos mais experientes, mas personagens notórios também ressurgiram, lançando candidaturas próprias ou apoiando candidaturas de outras pessoas.

Aparecida é um espaço de produção e de reprodução da fé católica e isso reflete na organização de seu território, visto pelos nomes religiosos católicos dos estabelecimentos e bairros da cidade, bem como na pertença religiosa de seus moradores à igreja romana, que chega a quase $90 \%$. A existência da cidade se deve ao fato de ter que cumprir uma função religiosa (FRANÇA, 1975). Guardar a Imagem de Maria, aparecida nas redes dos pobres pescadores nas águas do Rio Paraíba, destinou à então pequena capela reservada para a devoção da santa, ver nascer, ao longo dela, uma cidade, que não só serviria como ponto de passagem de seus devotos, mas uma estrutura voltada para o atendimento destes, que, ao longo dos anos, engrossavam a peregrinação visando conhecer a imagem da santa considerada milagrosa (BRUSTOLONI, 1998). Tal dinâmica se amplia quando a capela dá lugar a uma igreja no mesmo local, maior e que será a primeira Basílica da Santa, o mesmo acontecendo depois quando uma Nova Basílica é erguida, próxima da anterior ${ }^{2}$. Com o intuito de dar suporte à função religiosa do lugar, pousadas, hotéis, restaurantes e serviços das mais diversas ordens vão ganhar forte presença na cidade, que passa a demandar uma administração que pudesse dar conta de gerir a ocupação do território (GODOY, 2015; 2017). De uma forma geral, os problemas da cidade de Aparecida não são apenas de ordem religiosa, mas derivados da maneira como suas dinâmicas sociais e culturais emergem em torno da religião.

Se a cidade demanda a emergência de uma gestão que permita organizá-la, o modo de fazê-lo vai dividir Aparecida em grupos que vão, cada qual a seu modo, lutar para fazer valer o seu modo de organizar. Tal como pode ser encontrado em outros casos etnográficos (GOLDMAN; PALMEIRA, 1996; BARREIRA; PALMEIRA, 2006; HEREDIA; TEIXEIRA; BARREIRA, 2002), o processo eleitoral de 2016 que se deu na capital mariana permite observar um palco de disputas em relação aos rumos a serem tomados pela cidade, que permitiu com que propostas e projetos fossem endereçados e promovessem engajamentos. Em Aparecida, são muitas as vozes que vão procurar agregar em torno de si o máximo de adeptos possíveis visando assumir o único posto capaz de programar o tipo de administração pública desejada, a prefeitura. Esta vai ser o ponto de encontro das demandas dos cidadãos que a ela levam cotidianamente seus problemas, que passam pelo atendimento de necessidades locais pontuais a questões

A construção da Basílica nova foi iniciada em 1946, mas só foi consagrada no ano de 1980. 
que podem produzir modificação da estrutura da cidade. Também vai ser na prefeitura onde o Santuário, corriqueiramente reconhecido como o quarto poder da cidade (GODOY, 2017), vai pressionar pela resolução de problemas que vez ou outra ele identifica, quase sempre atrelado ao bem-estar do romeiro.

Iniciada a corrida eleitoral, dois conjuntos de problemas passam a ser fortemente tematizados, tanto pelos moradores quanto pelos clérigos do Santuário. Trânsito, segurança e saúde são questões que devem ser pensadas para atender aos moradores locais ao mesmo tempo em que devem atender às demandas dos romeiros. Estes últimos são em grande parte aqueles que mantêm a economia local. Por outro lado, a centralidade no atendimento ao romeiro não pode levar a uma exclusão do atendimento das demandas dos moradores locais, que, por sua vez, são aqueles que prestam o atendimento ao visitante e colaboram para sua satisfação e vontade de retorno. É em torno desses dois conjuntos de questões que são suscitadas muitas controvérsias, evidenciando o que Montero, Brum e Quintanilha (2016) chamam de públicos políticos, na medida em que aquelas questões mobilizam e engajam numerosos atores oriundos desde a esfera clerical até a temporal.

Apesar de o engajamento direto dos moradores na eleição ser pontual e tímido, os grupos que vão sendo formados, a partir e para as candidaturas a prefeito e vereador, movimentam a cidade. Bandeiras, adesivos, faixas, sons, placas e banners, estampados em carros e fachadas de casas e apartamentos que vão acusar o pertencimento a um grupo, marcam a cidade no tempo da política (BARREIRA, 1998). Por sua vez, espaços próximos a igrejas e comércios são acessados para serem lugares de campanha e, mesmo não tendo visto sequer uma bandeira, banner ou adesivo em hotéis, pousadas, restaurantes ou bares da cidade em favor de algum candidato, em alguns poucos estabelecimentos comerciais foi possível encontrar em seu interior "santinhos" de pleiteantes ao cargo de prefeito e vereador. Na Basílica, velha ou nova, bem como nas demais igrejas e capelas católicas da cidade, as campanhas se desdobram no entorno de seus muros, pelo menos em relação à entrega de materiais, mas são sempre pontos de passagem em qualquer caminhada dos candidatos pela cidade.

Por conta disso, podemos afirmar que os usos políticos desses espaços não são inviabilizados, haja vista que igrejas e comércios foram visitados por candidatos que nelas adentraram para pedir votos (no comércio) ou simplesmente serem vistos (em igrejas e também em alguns momentos no comércio). Isso porque, por um lado, muito do espaço público em Aparecida está entre estas duas esferas da vida: praças que se conformam como extensão de igrejas ou calçadas feitas para o atendimento do comércio ali desenvolvido. Por outro lado, porque esses lugares são parte da cidade e é preciso reconhecer a importância deles, fazendo-se presente e dando a eles significado para a vida da cidade: é nesses lugares em que os candidatos podem ser vistos pelos eleitores de Aparecida, na medida em que são espaços de presença constante dos moradores locais e por onde parte de suas vidas se realiza. Tal comportamento faz parte da dimensão imagética que perpassa as campanhas eleitorais (BALANDIER, 1982; ABÈLÉS, 1989), bem como das articulações que cada campanha procura estabelecer com os aspectos mais locais, no seu sentido geográfico, na qual ela se desenvolve (AGNEW, 1998).

Por fim, ao olharmos para a instituição Santuário, esta não se exime de tentar pautar o que vai ser debatido na cidade ao logo do processo eleitoral. O Santuário 
promove encontros, debates, encomenda pesquisas de opinião e intenção de voto, além de publicizar os meandros da disputa na cidade por meio de seu sistema de comunicação. Diante das necessidades em colocar em funcionamento determinados setores da cidade relacionados aos atendimentos ao morador e ao romeiro, cuja responsabilidade seria do poder público municipal, o Santuário aponta temas que levam ao engajamento na arena pública. Reconhecendo sua função pedagógica, tal como mostra a etnografia de Godoy $(2015 ; 2017)$ sobre a atuação do Santuário em Aparecida, o clero parece querer forçar a cidade a melhorar serviços e atendimentos, legitimando-se como a voz de moradores e romeiros. Ao fazer isso, mesmo que demostre uma preocupação com a cidade, o Santuário, ao borrar as fronteiras entre o religioso e o político, gera tensões que revelam a maneira como essas duas esferas da vida imbricam-se em Aparecida.

\section{As Candidaturas para o Poder Executivo}

Nas eleições de 2016, foram seis os candidatos que se lançaram a prefeito: Sargento Ernaldo (PMDB); Celso Alves (PDS); Jeffercy (PR); Toninho Barão (PHS); Gustavo Lopes (PEN); Paulo Caputo (PROS) ${ }^{3}$.

Paulo Caputo tinha 47 anos, casado, natural de Bananal, contador, e lançou-se à candidatura para a prefeitura de Aparecida pelo PROS com o lema "Renova Aparecida". Ele não possuía experiência política, mas apenas administrativa na esfera do mercado. Paulo Caputo fez uma campanha discreta. Seu material de campanha nas ruas era pouco e era possível contar nos dedos os adesivos em carros e em casas acusando adesão do eleitor. No material que coletamos sobre o candidato era possível ver sempre estampado o lema de sua campanha, "Renova Aparecida", ao lado da expressão "Chega de blábláblá", aludindo à necessidade de mudança no modo de gerir a cidade diante das promessas demasiadas em detrimento de ações efetivas em prol dela. Alegando ausência de recursos financeiros, a campanha dele resumiu-se a visitas e conversas com os moradores das comunidades de Aparecida. Tinha pouco espaço na televisão e rádio locais, e a maior visibilidade que possuía se dava ao longo das entrevistas e debates promovidos pela Rede Aparecida ou pela Rádio Monumental ${ }^{4}$. Não possuía correligionários suficientes que pudessem produzir volume em sua candidatura, sendo raras as bandeiras suas e de seu partido cruzando a cidade em carros de som que pudessem contagiar os olhares e ouvidos dos eleitores.

Entretanto, destaca-se em sua campanha a necessidade de se mostrar vinculado com o símbolo religioso maior da cidade, a imagem de Nossa Senhora Aparecida. Esta foi trazida como escudo estampado nas poucas camisas fabricadas para sua campanha,

\footnotetext{
Apesar de muitos partidos terem diretórios em Aparecida e lançarem seus candidatos, a pertença partidária não é levada em conta como retórica ou justificação no momento das eleições, seja por parte dos candidatos, seja por parte dos eleitores. A ideologia partidária dá lugar à notoriedade costurada ao longo do tempo por personagens que capitaneiam o que a antropologia da política chama de facção política (PALMEIRA, 1995; 1997). A grande quantidade de partidos pode ser explicada pela também grande quantidade de personagens que possuem graus diferentes de capital político que, concorrendo entre si, produzem alianças que modificam o tempo todo a maneira como a política é feita em cidades como Aparecida.

4 A Rádio Monumental é a segunda em audiência e sintonia em Aparecida. É bem menor e funciona como alternativa à hegemônica radiotransmissora católica.
} 
que propagandeavam mais o seu partido do que a própria candidatura. A imagem da santa também se fez presente em fotografias vinculadas à campanha, em que o candidato fez questão de veicular sua presença ao lado dela. Dois sentidos parecem despontar como plausíveis para esses atos: por um lado, como um sinal de busca de proteção para a jornada política na qual o candidato se lançara; por outro, como apelo à intimidade cultural da cidade, assentada na reverência à santa, apontando para a noção de que a legitimidade do futuro gestor está nela alicerçada. Terminada a apuração, Caputo não conseguiu mais que 535 votos (2,43\%), quantidade inferior ao número de votos nulos e brancos contados separadamente e menor até que o nono vereador mais votado.

Gustavo Lopes, jovem arquiteto de 31 anos, é natural de Aparecida e tem família ligada ao ramo de hotelaria, ao qual ele também esteve inserido. Se formou pela Universidade de Taubaté, obtendo posteriormente o título de mestre em Planejamento Urbano e Regional pela Universidade do Vale do Paraíba. Durante a graduação iniciou trabalho social e chegou a participar diretamente de organizações de comunidades e bairros, o que o levou a ocupar a Secretaria de Obras de Aparecida durante a gestão de Márcio Alves, cargo que teria lhe fornecido, segundo seu material de campanha, uma ampliação da percepção das demandas dos moradores da cidade de Aparecida. Em 2012, tinha sido candidato a vice-prefeito pelo PV, em chapa encabeçada por Ana Alice ${ }^{5}$. Em 2016, filiado ao PEN, lançou-se a prefeito com o lema "Renovação Já".

Gustavo Lopes fez uma campanha um pouco mais combativa. Procurou percorrer mais ativamente as ruas e os bairros de Aparecida, mesmo andando por ela sozinho e sem muita pompa. Desenvolveu um plano de governo bem apresentável, do ponto de vista imagético, por mais que esse plano tenha circulado apenas no formato on-line, sob a alegação de contenção de despesas e compromisso com o meio ambiente. Em alguns momentos da campanha, Gustavo Lopes pode contar com correligionários que percorriam a cidade vestindo sua camiseta, portando sua bandeira ou distribuindo seus santinhos. Não mais que dois carros de som e uma bicicleta com alto-falante foram colocados na rua e uma pequena carreata foi feita na última semana da campanha. "Renovação Já" era o lema e seu foco estava na elaboração de propostas sustentáveis para a cidade. Tal como Caputo, o acesso aos símbolos religiosos da cidade não deixou de se fazer presente. Porém, ao contrário do candidato anterior, que fez uso da Imagem da Santa, Gustavo Lopes fez uso da imagem da Basílica Nova, utilizada como pano de fundo dos adesivos da campanha, em que, além do nome e número do candidato, estava estampada a frase "Aparecida Merece Respeito". Mesmo usando um pouco mais de recursos e criatividade, o volume de sua campanha foi incipiente e acabou não contagiando o eleitorado local de forma a garantir seu êxito no escrutínio, tendo acabado em penúltimo lugar na disputa, com 1.231 votos $(5,59 \%)$.

Antônio de Pádua dos Santos Gomes, o Toninho Barão, com 53 anos, casado, natural de Aparecida, empresário do ramo de automotivos na cidade, não possuía experiência no campo político. Porém, em sua biografia espalhada por meio de panfletos, o candidato reforça sua origem como nativo da cidade e empresário de sucesso, que o credencia

5 Ana Alice foi candidata a prefeita nas eleições de 2008 e 2012, obtendo respectivamente 934 e 1.998 votos. Em 2016 se lançou a vereadora, quando conquistou 1.252 votos, o que lhe deu a posição de vereadora mais votada da cidade. 
como entendedor das demandas dos munícipes e capacitado como gestor ${ }^{6}$. O desejo dele, segundo sua propaganda política, era o de servir a população, ao mesmo tempo transmitindo suas qualidades empresariais para a administração do município. Nessa sua primeira candidatura, ele lançou-se pelo PHS, propalando o lema "quem ama cuida". Toninho Barão desenvolveu uma campanha mais efetiva dos que os anteriormente citados. Tinha carros de som nas ruas, pessoas flamejando suas bandeiras em algumas praças da cidade e conseguiu organizar uma carreata com algumas dezenas de participantes, bem como procurou entregar seu plano de governo impresso a partir de seu comitê localizado na Praça São Benedito, no centro da cidade, ou nos encontros que tinha com seu eleitorado em potencial. Percorreu os bairros da cidade junto com seus correligionários, que distribuíam seu material de campanha enquanto ele conversava com os moradores locais. Com seu lema "quem ama cuida", aproveitou o contato com as comunidades para fotografar e denunciar as mazelas de cada bairro: praças abandonadas e tomadas pelo mato, obras inacabadas, terrenos baldios cheios de lixo e sujeira e descaso com o patrimônio da cidade.

Ao contrário de Caputo e Gustavo, as atividades de campanha de Toninho Barão tinham bom público, o que certamente justifica muitas casas e carros nos bairros da cidade com adesivos de sua candidatura. Entretanto, um dos principais contatos com o eleitor, que se dava por meio de um comitê fixado temporariamente na praça São Benedito, no centro da cidade, levou a campanha a pairar num imobilismo. A intenção era que ali Toninho Barão pudesse aguardar o contato do eleitor e conversar com ele, mas isso raramente acontecia, deixando o candidato conviver com uma campanha para si mesmo, amparado por correligionários, mas sem impactar o eleitorado que passava ao longo da praça. Fez pouco uso dos elementos religiosos da cidade, evidenciando no seu plano apenas a imagem da Basílica Nova, que se posicionava no canto superior esquerdo do seu panfleto ${ }^{7}$. Ao final das eleições, o quarto lugar conquistado, com 1.261 votos $(5,72 \%)$, refletiu, em parte, a (in)capacidade do candidato de atingir ampla parcela do eleitorado local.

Jeffercy de Souza Nunes Chad, 52 anos, casada, natural de Aparecida e engenheira, atuou como Diretora do departamento de obras de Aparecida na gestão Zé Louquinho, entre os anos 2005-2008. Posteriormente, foi candidata a vice-prefeita, em 2012, com Zé Louquinho para prefeito, chapa impugnada logo após o fim do escrutínio que elegera mais uma vez esse emblemático político regional. Em 2016, Jeffercy lançou-se candidata a prefeita pela coligação "Mudar para ser Feliz", composta de seu partido PR e do PSB. A trajetória de sua campanha é reforçada pelo carisma do antigo prefeito e também pela sua atuação na presidência do PR Mulher de Aparecida/SP. Jeffercy fez uma das campanhas mais combativas da cidade. Não lançou mão dos símbolos religiosos da

\footnotetext{
6 O trabalho de Coradini (2009) discorre sobre a maneira como as origens e os recursos sociais dos candidatos têm passado pela ocorrência do uso da especialização profissional, que é lançada como forma de endereçar o sentido da campanha e da representação política.

7 Entretanto, não se pode desconsiderar o fato de que seu partido foi reduto de muitos candidatos oriundos de movimentos religiosos, especialmente da Renovação Carismática Católica, o que marcou a composição ideológica do partido. Esses elementos não apareceram na campanha de 2016, mas se seus membros acreditavam que portavam um projeto político e religioso, acessando elementos religiosos numa cidade concebida como religiosa poderia parecer redundante.
} 
cidade na produção imagética de sua campanha e ancorou-se no já mencionado capital político do Zé Louquinho.

A candidata procurou acessar os problemas dos moradores da cidade a partir de uma diversificada campanha. Percorreu a cidade montando comitês itinerantes, tendas decoradas com faixas da candidata, que contavam com um amplificador que tocava os jingles da campanha e uma pequena mesa na qual se avolumavam adesivos, santinhos, bandeirinhas, folders e plano de governo para serem distribuídos aos passantes. Esses comitês itinerantes eram montados de manhã e desmontados no final da tarde. Nesses dois momentos, Jeffercy estava presente, procurando conversar com os moradores dos bairros, sempre rodeada de correligionários que distribuíam o material de campanha ou tremulavam sua bandeira. Antes de ser implementado, o comitê era anunciado previamente, por meio de panfletos e de carros de som que passavam pelo bairro. Diferentemente de Toninho Barão, Jeffercy tinha a iniciativa de se aproximar do(a) eleitor(a) que passava pelo comitê, procurando conversar com ele(a) e mostrar suas propostas. Essa atividade era alternada com caminhadas, visitas e reuniões com moradores de cada um dos bairros de Aparecida, sempre realizado com a presença de seu principal cabo eleitoral e de correligionários. Além disso, Jeffercy tinha tempo razoável no horário eleitoral gratuito na rádio e na televisão locais, que era ocupado quase que totalmente pelas falas de Zé Louquinho, que ora elencava seus feitos quando prefeito, ora criticava o modelo de gestão vigente na cidade. Entretanto, os limites orçamentários da campanha produziram uma propaganda inerte nessas mídias e com escassos recursos imagéticos. Isso era compensado com a movimentação de redes de apoio, como a visita de dois deputados de seu partido a um de seus comitês itinerantes, o deputado estadual André do Prado e o deputado federal Márcio Alvino, que ali foram prestar apoio à candidatura dela. Nesse evento, o anúncio prévio da presença dos deputados levou à instauração de um palanque adaptado na calçada, convertendo o momento em um comício que aglutinou centenas de pessoas, que se solidarizavam com a candidatura e ouviam as declarações de apoio dos deputados e de Zé Louquinho. Este último era personagem principal, como na maioria dos eventos da candidatura, mostrando-se, ao mesmo tempo, locutor e orador. Apesar dos esforços empreendidos, contados os votos, ela obteve 19,89\% da preferência dos eleitores locais (4.384 votos), ficando em terceiro lugar na disputa pela prefeitura.

Celso Alves, com 39 anos, solteiro, comerciante e natural de Aparecida, foi vereador na legislatura 2009-2012 e tinha participado da corrida eleitoral para a prefeitura em 2012, sem obter êxito. Em 2016, concorria novamente ao cargo do executivo com a coligação "Respeito por Aparecida", composta dos partidos PP, PTN, PSC, PSD, PRB, PSDC e PRB. Seu mote de campanha era a defesa da renovação como forma de atuação na relação da prefeitura com o aparecidense, por meio de uma participação mais ativa e inclusiva. Para tanto, procurou percorrer os bairros da cidade durante as convenções de seu partido, debatendo e elaborando um plano de governo, expressando a necessidade de realizar uma grande mudança na cidade, convidando todos a caminhar juntos com o projeto de renovação política de Aparecida. A ideia de renovação aparecerá nos jingles e nos esforços de marcar a diferença entre sua candidatura e as demais que foram apresentadas para a cidade, especialmente as relacionadas ao atual grupo mandatário do município. Os apoios recebidos externamente foram bastante expressivos, como a do Governador do Estado 
de São Paulo Geraldo Alckmin (PSDB) e do deputado estadual Padre Afonso Lobato (PV). Este último chegou a estar em Aparecida em uma das atividades de campanha do candidato. Ainda, contou com apoios de deputados federais e estaduais dos partidos de sua coligação que foram divulgados nos programas eleitorais na rádio e na televisão.

Os usos dos recursos simbólicos ligados à religiosidade da cidade foram bem ativados na campanha de Celso Alves. Suas convenções contavam com a imagem de Nossa Senhora Aparecida sobre a mesa, a quem sempre fazia referência. As propagandas nas mídias impressa e audiovisual lançavam mão de metáforas bíblicas ou do fato de que a cidade era uma terra abençoada, ponto de irrupção de fé e esperança, que atribuía à cidade um lugar de destaque para a vida não só dos aparecidenses, mas de todos os brasileiros. É por isso que nos folhetos e vídeos a imagem das Basílicas velha e nova, as igrejas dos bairros e do Rio Paraíba, onde foi achada a imagem que foi tomada como milagrosa, aparecem com grande destaque. A importância da catolicidade da cidade na campanha de Celso levou o candidato a percorrer ruas e espaços que possuíam função religiosa, bem como comparecer a festas e romarias, que, por mais que fosse limitada a participação dele como pessoa religiosa, demonstrava um reconhecimento do político com o acontecimento. Seus esforços lhe renderam o segundo lugar no pleito, com 7.238 votos $(32,84 \%)$.

Sargento Ernaldo, 52 anos, casado, militar reformado, elegeu-se em 2004 como vereador, tendo sido presidente da Câmara Municipal no biênio 2005/2006. Participou das eleições majoritárias da cidade nos dois últimos pleitos, 2008 e 2012. Em 2008, como candidato pelo PDT, ficou em terceiro lugar. Em 2012, como vice-prefeito na chapa de Márcio Siqueira, conquistou a prefeitura, com a resolução do processo eleitoral que caçou a chapa vitoriosa encabeçada por Zé Louquinho. Em 2015, Ernaldo, com o afastamento temporário, por força da justiça, de Marcio Siqueira, tomou a frente do executivo municipal, exercendo a função interinamente até meados de 2016. Em 2016, agora pelo PMDB, com a coligação "Aparecida no caminho certo", formada por PDT, PT, PTB, DEM, PSR, PPS, SOLIDARIEDADE, PCdoB, PV e PRTB, lançou-se novamente como postulante a exercer as funções administrativas do município. Sua campanha foi marcada pela organização de grandes eventos, com uma convenção e uma carreata que reuniram milhares de pessoas, além da defesa da gestão que realizou durante alguns meses na cidade e a preocupação em reforçar o papel da mulher na política, que fez com que tivesse Dina da APAE como sua vice e firmasse o compromisso de nomear mulheres para metade das secretarias da prefeitura. Nas ruas, procurou percorrer os bairros com caminhadas, visitas e reuniões com os moradores, assim buscava propalar o que chamou "corrente do bem", cuja intenção era construir uma cidade melhor, colocando, como sugeria, Aparecida no caminho certo. Além do forte apoio popular, contou com o respaldo de deputados federais do Estado de São Paulo e da declaração aberta de um frei católico, que havia sido diretor da Santa Casa da cidade.

As referências à catolicidade da cidade ganharam várias frentes. A convenção que efetivou sua candidatura foi realizada diante da imagem da padroeira, exibida em um púlpito que se posicionava à frente da mesa em que as falas eram feitas. Suas propagadas audiovisuais traziam vários panoramas da cidade, que se concentravam em marcar os aspectos religiosos, como o Rio Paraíba, a Basílica Velha e a Basílica Nova. 
Essa ligação, religiosamente orientada, desdobrava-se nas falas em encontros e comícios, que evidenciavam o caráter abençoado e acolhedor da cidade, o que sugeria a necessidade de um cuidado com ela, e nos jingles que propalavam a condição de homem de fé e benfazeja do candidato. Ao final da contagem dos votos, Ernaldo foi o preferido dos eleitores, atingindo 7.388 votos $(33,53 \%)$.

Celso Alves e Sargento Ernaldo fizeram um uso expressivo dos elementos religiosos que atravessam o imaginário local. Foram também, junto com Jeffercy, os que mais estiveram nas ruas procurando atingir o eleitorado, com caminhadas, reuniões, bandeiraços e panfletagens. Essas três últimas candidaturas são as que mais tiveram carros de som nas ruas e material de campanha distribuído e adesivos pregados em carros e casas. Entretanto, em termos de identificação com a cidade, Celso e Ernaldo produziram uma retórica mais efetiva, mobilizando em seu favor os sentidos da cidade em termos de sua função religiosa e os problemas que a Aparecida se defrontava no momento em termos de saúde, segurança e trânsito.

Essas duas candidaturas apresentaram-se como exemplos da imbricada relação entre identidade, política e religião que é possível encontrar na cidade. Elas acessam os símbolos religiosos a partir de várias dimensões. Os candidatos são filmados e fotografados em capelas dos bairros e nas basílicas velha e nova da cidade. Marcam essa presença religiosa em seus materiais de campanha, dando a ideia de que o catolicismo habita fortemente aquele lugar. Seus jingles e o comportamento ao longo da campanha procuraram colocá-los como homens de fé e que estão a serviço da cidade marcada pela religião. Essa atenção pela cidade religiosa é estendida não apenas para a preocupação que tem em atender às demandas relacionados à presença dos romeiros como também para os bairros e moradores de Aparecida, que carecem de ação do poder público para satisfazerem demandas relacionadas à saúde, à segurança e ao transporte. Por conta das semelhanças em termos de retórica de campanha, Ernaldo e Celso dividiram o centro das atenções nos confrontos apresentados nos debates em rádio e TV e também a preferência do eleitor aparecidense. Ao final do escrutínio e com uma diferença de apenas 150 votos, Ernaldo saiu vencedor ${ }^{8}$.

\section{Papel do Santuário nas Eleições Municipais}

O Santuário Nacional, por mais que não declarasse apoio a um ou outro candidato, tem papel de destaque no processo de escolha do administrador do município. Alguns eventos que promoveu ajudam a mostrar essa presença política do Santuário, se destacando: uma reunião dos candidatos a prefeito com o Arcebispo na Cúria Diocesana; dois debates entre os prefeitáveis na Rede Aparecida de Televisão; divulgação de pesquisa de intenção de votos para prefeito. Essa participação nas eleições recolocou a maneira como as esferas religiosa e política se articulam em um espaço cuja existência em muito se justifica pela presença de elementos que são tomados como sagrados. Por um lado, não podemos deixar de acentuar que essas relações são marcadas por uma tensão, que antagonizam as percepções que se tem sobre a cidade e que podem ser vistas nas posições dos clérigos,

\footnotetext{
8 O número de abstenções chegou a 5.571 votos. Brancos e Nulos somaram 1.891 votos.
} 
candidatos, fiéis e eleitores: as escolhas na gestão pública e as demandas a serem atendidas esbarram em interesses diversos, limitando a ação pública e contrariando interesses dos envolvidos; quem vota é o eleitor e não se pode deixá-lo sempre em segundo plano quando a questão é a intervenção na paisagem urbana; entretanto, não se pode deixar de levar em conta aquilo que as instituições e as corporações demandam porque mobilizam recursos materiais e simbólicos que podem minar o poder municipal. Por outro lado, é preciso considerar que essa relação entre a esfera religiosa e a política leva a níveis de colaboração. Nesse caso, são os clérigos que se tornam porta-vozes da comunidade de fiéis e eleitores, falando por eles ou convidando-os para falar de suas necessidades. Mas são também os políticos que vão encontrar na esfera religiosa um ponto de canalização de projetos e recepção de demandas, já que não pode ser negligenciada a força do Santuário em termos sociais e econômicos, bem como sua capacidade de mobilizar e engajar a cidade em torno de interesses coletivos.

O primeiro evento acima elencado, a reunião dos candidatos a prefeito e a viceprefeito com Dom Raymundo Damasceno, Arcebispo de Aparecida, foi realizado na noite do dia 12 de setembro de 2016, segunda-feira, em um salão da Cúria. Todos os candidatos estiveram presentes para discutir os problemas do município e os desafios para os próximos quatro anos. Além dos candidatos, estiveram presentes no evento os párocos de três paróquias de Aparecida: Padre José Antônio Dal Bó (Nossa Senhora Aparecida); Padre Jalmir Carlos Herédia (Santo Afonso) e Padre Lauro Firmino (São Roque), o Reitor do Santuário Nacional, Padre João Batista de Almeida, e o administrador da Santa Casa, Frei Felipe Salatiel. O evento foi noticiado no site da Rede Aparecida, que procurou salientar que o encontro serviu para confrontar os candidatos com as necessidades das comunidades, que foram trazidas pelos párocos. O papel da igreja católica para a cidade foi acentuado no noticiário relacionado ao acontecimento, especialmente como porta-voz de demandas populares como saúde, educação e lazer. O noticiário relatou que na reunião foi reforçada a necessidade de se fazer uma gestão que possa envolver investimento em todo o município, integrando a cidade, e permitir com que os recursos possam circular em todos os bairros. Tal evento foi posteriormente divulgado pelos candidatos em suas páginas na internet, sinalizando demonstração de reconhecimento e de interesse em debater os problemas da cidade com o Santuário.

Além dessa reunião, o Santuário, por meio da Rede Aparecida, organizou e transmitiu dois debates entre os candidatos à prefeitura de Aparecida. O primeiro foi realizado no dia 31 de agosto, às 9 horas da manhã, e o segundo no dia 29 de setembro, às 9 horas da noite. Esses dois debates foram transmitidos localmente com faixa de frequência direcionada aos munícipes pela rádio e também por meio da página oficial da emissora na rede social facebook, por videotransmissão. Ambos contaram com a presença dos seis candidatos a prefeito. De uma forma geral, o debate levantou temas ligados diretamente às demandas do município, em que cada candidato podia apresentar genericamente suas propostas e serviu como mais um meio de contato do eleitor com os candidatos bem como destes entre si, confrontando propostas e ideias. A cobertura de cada um desses debates teve duração de aproximadamente duas horas, com cinco blocos divididos em momentos com perguntas elaboradas por representantes do Santuário, advindas dos moradores de Aparecida, e perguntas feitas entre os próprios candidatos. 
Ao organizar um debate envolvendo os candidatos a prefeito na cidade de Aparecida, o Santuário atua de forma ambivalente. Por um lado, coloca-se como interessado na formação política em geral pelas seguintes razões: ao ajuntar sob sua rede de comunicação políticos dos quais sairá o administrador da cidade pelos próximos quatro anos, permitindo com que falem à comunidade local; ao abrir espaço para os eleitores indagarem os prefeitáveis com questões sobre a cidade em geral; ao permitir com que os candidatos confrontem suas ideias e projetos sobre a cidade, em que cada qual elabora e apresenta a maneira como pensam a gestão municipal. Por outro lado, o Santuário não se furta de pautar parte do debate: na medida em que endereça questões a cada um dos candidatos, fazendo uso dos especialistas em comunicação que trabalham na sua emissora; quando membros do clero vinculado ao Santuário lançam questões aos aspirantes a prefeito e dão, pela notoriedade que possuem, legitimidade ainda maior à pergunta feita, exigindo com isso melhor desenvoltura e retidão em relação à resposta a ser devolvida, uma vez que pode implicar sinal de mais ou de menos compromisso com aquele que pergunta.

Nas duas ocasiões de confronto entre os candidatos, a mediação ficou a cargo do jornalista André Costa, vinculado à Rede Aparecida de Comunicação, sinalizando uma dimensão de cobertura política para o debate em consonância com a moda jornalística vigente no país. Tal impressão só volta a ser dada quando o jornalista da Rede Aparecida faz uma pergunta aos candidatos. Entretanto, também nesses dois momentos, a primeira fala para os candidatos era feita pelo superintendente da emissora, Padre Evaldo Souza, trajando hábito eclesiástico, que apresentava a importância do debate e endereçava aos candidatos alguma pergunta. Esse tipo de comportamento sugere que há um interesse em pautar o debate por parte do Santuário, o que pode ser reforçado com a presença de outros clérigos que também fazem o papel de interrogadores. Entre esses nomes estão o do administrador da Santa Casa de Aparecida (Frei Felipe Salatiel), o reitor do Santuário Nacional (Padre João Batista de Almeida), o diretor administrativo da Rede Aparecida de Comunicação, missionário redentorista e diretor administrativo da Fundação Nossa Senhora Aparecida (Padre José de Vilas Boas), o Cardeal Arcebispo de Aparecida (Dom Raymundo Damasceno Assis), o administrador-ecônomo do Santuário Nacional de Aparecida (Padre Daniel Antônio da Silva). A ingerência da religião em assuntos públicos que pode ser sugerida nessa postura dos clérigos é relativizada quando se atenta para o tipo de pergunta realizada. Mesmo que algumas questões sejam de interesse do Santuário, o diálogo procura expressar questões advindas do eleitorado, na medida em que alguns clérigos se apresentam como que falando em nome da população com a qual estabelecem contato, atuando como mediadores entre esta e os candidatos.

No primeiro debate, quando Padre Evaldo toma a palavra, ele a utiliza para enfatizar o trabalho de conscientização do cidadão que é realizada pela Rede Aparecida, expressado no debate por ela promovido, para, em seguida, perguntar aos candidatos sobre a questão da feira livre da cidade 9 . Sua questão passava pela desorganização do espaço, sem transparência e que atrapalha a circulação de veículos e pessoas no coração da cidade e desejava saber as propostas dos candidatos para o problema. Ao longo do debate, outros clérigos foram convidados a tomar a palavra e a endereçar questões para os candidatos.

A etnografia de Godoy (2015), realizada no ano de 2013, já apontava para a persistência das tensões relacionadas à questão da feira livre e à manutenção da Santa Casa no cotidiano da cidade. 
O Administrador da Santa Casa perguntou sobre custeio do atendimento da Santa Casa, que atende a população local, a população das cidades vizinhas e também os romeiros que visitam a cidade durante todo o ano. Segundo o administrador haveria um déficit, fruto da falta de repasses, que estaria prejudicando a qualidade dos atendimentos. O Reitor do Santuário Nacional, por sua vez, fez duas perguntas. A primeira se o candidato é ficha limpa e a segunda sobre as propostas dos candidatos sobre a geração de emprego e renda na cidade, uma vez que há falta de emprego em Aparecida para além das oportunidades oferecidas pelo Santuário. Por fim, o Diretor Administrativo da Fundação Nossa Senhora Aparecida indagou os candidatos sobre suas propostas para ordenar o comércio, garantindo a organização e a segurança da cidade. Para esse clérigo, não existiria fiscalização no setor, fazendo com que aumentasse a insatisfação do romeiro diante da exposição de mercadorias nas calçadas e de também andarilhos pelas ruas, principalmente na região da Basílica.

No segundo debate, Padre Evaldo, após aplicar um sermão aos candidatos em prol da civilidade na condução do debate, diante dos atritos entre eles no debate anterior promovido pele Rede Aparecida, bem como no promovido pela Rádio Monumental, perguntou aos candidatos sobre seus posicionamentos e seus projetos para a organização da cidade que contemplassem o crescimento ordenado, manutenção do que já existe e a preocupação com os romeiros que chegam diariamente, especialmente em razão da comemoração dos 300 anos da devoção mariana da região. O Arcebispo de Aparecida, quando convidado para participar do debate, demandou saber sobre projeto dos prefeitáveis para o Pronto Atendimento da cidade, que funciona na Santa Casa. Tal como no debate anterior, a questão passou pela situação deficitária da instituição, causada pela falta dos repasses por parte da prefeitura, que, de acordo com Dom Raymundo, seria a responsável pelo setor na Santa Casa. Por fim, o Administrador-econômico indagou sobre como cada candidato pensava melhorias concretas relacionadas à recepção e à infraestrutura da cidade para a celebração dos 300 anos da Padroeira no ano de 2017. Reforçou, ainda, que o Santuário tem feito sua parte no que tange ao investimento na acolhida aos romeiros, justificando o mote propalado pela instituição, "acolher bem também é evangelizar", que significava um atendimento desde a entrada na cidade pelos romeiros ao acolhimento dentro dos muros do templo. Por outro lado, acentuou que é necessário a prefeitura fazer sua parte nesse projeto de acolhimento, investindo em estacionamento, limpeza da cidade, em pessoal treinado para receber os visitantes, em infraestrutura de segurança e, principalmente, em banheiros públicos.

Nos dois debates, diante das perguntas endereçadas, os candidatos reagiram conforme a conveniência. Em quase todos os casos, eles agradeceram pela pergunta feita, asseguraram que seriam parceiros do Santuário na administração do município e procuraram responder o questionamento. A questão da feira, por exemplo, permitiu com que candidatos como Jeffercy e Celso Alves atacassem os descasos da prefeitura, acusando Ernaldo, que era prefeito interino, por parte dos problemas. Comprometeram-se em investir na feira e melhorar a vida dos feirantes e dos romeiros que circulam por ela, planejando melhor a distribuição das barracas, a segurança e a higiene. Nessa mesma direção foram as falas de Caputo, Gustavo Lopes e Toninho Barão, que disseram que investir nesses aspectos é fundamental para garantir a sustentabilidade do comércio ambulante que se realiza às 
portas da Basílica Nova. Ernaldo, por sua vez, buscou ressaltar que estes investimentos já vinham sendo feitos, especialmente durante o tempo que foi prefeito, o que acarretou numa melhora na circulação e no serviço oferecido na região da feira.

Os temas da Santa Casa, da geração de emprego e renda, da gestão do comércio, o planejamento urbano e os investimentos em infraestrutura para receber as festividades relacionadas aos 300 anos de devoção em Aparecida foram outras questões que mobilizaram o imaginário local e impactaram a resposta dos candidatos. Suas respostas e projetos, entretanto, acabavam seguindo um patamar demasiadamente genérico. Saúde sempre é prioridade para os postulantes a prefeito e todos são unânimes em reconhecer os trabalhos realizados pela Santa Casa nessa área, bem como em entender a necessidade de se desvincular o Pronto-Atendimento, de responsabilidade da prefeitura, dos demais serviços oferecidos pela Santa Casa, que, em parte, são custeados por recursos repassados diretamente pelos governos federal e estadual. O planejamento da cidade é sempre entendido como uma ação que deve contemplar não apenas as regiões centrais, mas todo o município. Os candidatos procuraram não sinalizar as prioridades dos investimentos públicos, mas reconheceram que há problemas relacionados à coleta de lixo, ao tratamento de esgoto e à limpeza de ruas e terrenos. A ordem das opiniões dos candidatos oscilou entre aqueles que disseram que já fizeram isso quando estiveram à frente de funções no executivo na prefeitura e aqueles que criticaram a má execução dos serviços básicos oferecidos na cidade. Já sobre a questão dos investimentos para a comemoração dos 300 anos de devoção, três posições emergiram: Caputo, Gustavo Lopes e Toninho Barão mostraram-se realistas ao ponto de dizer que não há tempo para fazer grandes intervenções, apenas investir no básico, como limpeza e iluminação; Celso Alves e Jeffercy criticaram os descasos com a data comemorativa que se aproximava e assumiram que eram capazes de mobilizar recursos para intervenção na cidade até a data da festa; Sargento Ernaldo, por sua vez, afirmou que já havia encaminhado, quando prefeito interino, os procedimentos para arrecadar recursos para investir na cidade no ano de 2017 e dar conta de modificar a cidade para acolher os romeiros.

Por fim, o último evento que marcou as eleições em Aparecida, envolvendo o Santuário, se deu ao final do segundo debate, quando a Rede Aparecida divulgou uma pesquisa de intenção de voto para prefeito. Durante a transmissão, os dados foram anunciados pelo Padre Evaldo, que após explicar os procedimentos da pesquisa e sua margem de erro, que era de 5\%, deu ênfase aos números relacionados ao voto espontâneo e rejeição do eleitorado aparecidense em relação aos candidatos. No primeiro caso, Sargento Ernaldo aparece com 22,5\% das intenções de voto, seguido por Celso Alves com 17,3\%, Jeffercy com 12,8\%, Toninho Barão com 5,5\%, Gustavo Lopes com 2,5\%, Paulinho Caputo com $0,5 \%$ e brancos e nulos com 7\%. O Padre, na ocasião, ainda ressaltou a grande percentagem de eleitores indecisos, que na pesquisa chegou a $32 \%$ dos entrevistados, o que daria um caráter indeterminado para as eleições, de acordo com o clérigo. No segundo caso, a pesquisa divulgada levou a uma rejeição maior em relação ao próprio Sargento Ernaldo, que atingia 20,5\% dos entrevistados, seguido por Jeffercy (17,5\%), Celso Alves (13,3\%), Paulinho Caputo (12\%), Toninho Barão (10,8\%) e Gustavo Lopes (10\%). Foi destacado também que entre os entrevistados o percentual daqueles que não rejeitam a nenhum candidato chega a $41,8 \%$, enquanto apenas $6,3 \%$ rejeitam todos os candidatos. 
A divulgação dessa pesquisa escancarou as tensões na cidade, na medida em que foi apropriada para diversas direções. Na observação realizada junto aos correligionários que acampavam em frente à sede da Rede Aparecida, à espera de seus candidatos, a sensação em relação à pesquisa era ambígua. Independentemente da compreensão do que seja uma pesquisa de intenção de voto e das lógicas que se escondem por trás da tabulação de dados coletados via amostragem, os presentes se mostravam cheios de ânimo e empolgação, quando seu candidato despontava na pesquisa, ou perplexidade e apatia, quando seus candidatos estavam atrás na disputa. Ao longo da noite, as candidaturas não deixaram de programar o dia seguinte, com o propósito de ampliar, manter ou reverter a lógica dos números. No dia seguinte, os candidatos foram às ruas e levaram seus correligionários. Zé Louquinho, que apoiava Jeffercy, chegou a convocar uma caminhada pelas ruas da cidade na manhã de sábado, visando reverter votos a favor de sua candidata e/ou conquistar os votos indecisos, que, pela pesquisa, eram muitos. Nas redes sociais, a empolgação com a vitória eminente de um dos candidatos andava junto com as críticas à pesquisa e a acusação da falta de sentido dela, uma vez que o candidato que se queria ver na frente não era o candidato do internauta. Na manhã de sábado, a pesquisa foi assunto na cidade. Nas ruas e praças, bem como na Rádio Monumental, não se falava de outra coisa. Alguns moradores da cidade questionavam a validade da pesquisa, duvidando da competência da empresa que a realizou, ou argumentavam enfaticamente que o resultado expressava a vontade do Santuário, que queria ver na prefeitura um dos candidatos, sem dizer seu nome abertamente. A Rede Aparecida, por sua vez, não só divulgou todo o material da pesquisa na internet como comentou em um dos seus programas de sábado seu conteúdo e formulação.

\section{Considerações Finais}

Os achados apresentados ao longo deste texto mostram como atores individuais, organizacionais e institucionais engajavam-se nas eleições em Aparecida para expressar, discutir e julgar opiniões sobre os problemas e rumos da cidade. Nesse momento, o que foi colocado em jogo passou pela localização de problemas a serem enfrentados, as disputas em torno da direção a ser tomada, promovendo polêmicas e controvérsias, mas também assinalando soluções e compromissos diante de conflitos. Aparecida se via imersa em um conjunto de problemas que passavam pela expectativa das comemorações do terceiro centenário da imagem de sua padroeira e pela instabilidade política e administrativa do município devido à mudança constante de prefeitos. Mas também era revolvida por problemas que atingiam corriqueiramente seu cotidiano, como o atendimento ao morador e ao romeiro em termos de saúde, mobilidade e organização, sem contar com a presença do Santuário, que tencionava frequentemente o funcionamento da política aparecidense com suas demandas e posicionamentos.

Tomando a eleição para prefeito em Aparecida e valorizando a dimensão das práticas dos atores engajados nas eleições, como sustentam os trabalhos de Goldman (2006) e Paley (2008), conseguimos perceber como são produzidos públicos políticos. Candidatos a prefeito se mobilizam por meio de recursos imagéticos e performativos que colocam 
em evidência os aspectos de intimidade da cidade, seja em matéria de religiosidade ou de tratamento de problemas de ordem social. A aproximação do eleitorado dependeu de uma boa dose de retórica que conseguisse promover a adesão à campanha do candidato, seja abertamente com a declaração de voto, seja secretamente como confiança depositada na urna. Nesse ínterim, o Santuário performa-se como espectro, vigiando ou tutelando o desdobramento das campanhas. Diluindo as fronteiras entre religioso e político, o Santuário fala em nome de moradores e romeiros para direcionar os temas que deveriam ser levados em conta. Ao agir de tal maneira, essa instituição evidencia os dilemas que diz observar no cotidiano dos aparecidenses. Esses dilemas, durante as eleições, são passíveis de serem reveladas em momentos de suspensão, como podemos observar nos desdobramentos das eleições em outros contextos etnográficos (PALMEIRA; HEREDIA, 2010).

Ao lançarem como recurso imagético as imagens da Virgem de Aparecida, das Basílicas, do Rio Paraíba, bem como de outras igrejas, os candidatos fizeram uso de um conjunto de símbolos que evidenciam e caracterizam a cidade, acionando o que Herzfeld (2014) chamou de intimidade cultural. A etnografia de Godoy $(2015 ; 2017)$ mostra muito bem como essa simbologia mariana e católica atravessa o cotidiano aparecidense, sendo invocada como signo de reconhecimento e pertença. Olhando pelo lado das práticas de campanha, temos exemplos de uso da linguagem religiosa no processo de produção de repertórios cívicos, no mesmo sentido que mostra o trabalho de Montero, Brum e Quintanilha (2016) para o caso das celebrações da Catedral da Sé. Em Aparecida, os candidatos pretendem mostrar algum grau de reverência e de intimidade para com o símbolo maior da cidade. Panfletos e bandeiras estampados com a imagem da Santa ou de suas Basílicas, caminhadas e carreatas por espaços marcados pela religiosidade, propagandas evidenciando lugares santificados. Uma cidade que nasceu em razão da emergência e da consolidação de uma devoção mariana, marcando suas funções em termos de religião, não poderia eximir seu corpo político, quando estabelecido, de recorrer a esta condição para justificar suas intenções políticas.

Essa imagética ressoou sobre as performances, quando os diálogos e os compromissos com o Santuário foram valorizados nas retóricas de campanha ou jingles e movimentações, ressaltando os aspectos mais religiosos da cidade ou a condição de "crente" do candidato. Por mais que existam tensões e embates entre Santuário e prefeitura, como mostra Godoy $(2015 ; 2017)$, não se pode deixar de notar a inclinação dos candidatos nas eleições de 2016 ao reconhecimento do papel do Santuário em Aparecida, especialmente em termos da saúde e da economia. Ao mesmo tempo, espaços consagrados foram pontos de passagem obrigatórios, reforçando os vínculos e marcando a pertença dos candidatos. As campanhas eleitorais, especialmente por meio de caminhadas e instalação de comitês, procuraram reconhecer pontos estratégicos que possibilitavam não só o acesso ao eleitor, mas a publicização do reconhecimento que o candidato confere ao lugar onde a ação está sendo executada (PROCÓPIO, 2014). Os espaços de peregrinação e penitência religiosa em Aparecida convertem-se em lugares de promoção de candidaturas, em grande medida devido ao préstimo que os candidatos têm pelos locais por onde decidem passar.

Mas se a cidade foi feita em benefício da devoção mariana, o que justifica a passagem pelos marcos dessa devoção, não é só de questões decorrentes das demandas da religião 
que a prefeitura vai ter que se ocupar ${ }^{10}$. Saber das dificuldades dos moradores para além da religião endereça as performances em outra direção, voltando-se para os problemas ordinários de Aparecida. Basta olharmos para os lemas das campanhas, que salientam os descasos com a cidade e a população e focalizam a necessidade do cuidado, para entendermos os esforços dos candidatos em denunciar as mazelas. Os eventos das campanhas não se eximem das andanças pela cidade para mostrar problemas e conversar com o eleitor. Nas franjas do Santuário, os candidatos à prefeitura se vêm na obrigação de buscar uma Aparecida profunda, para além daquilo relacionado a sua função religiosa, verbalizando os desmandos em matéria de saúde, saneamento e lazer, que foram exibidos nos encontros com o eleitor ou no debate com seus adversários. Essa outra gramática cívica, deslocada da dimensão religiosa que engaja a cidade, foi motivo de contenda e dividiu Aparecida em segmentos que se conformaram em adesões distintas até o final do escrutínio.

A atuação do Santuário no pleito, por sua vez, manteve-se sintonizada com a relação ambígua que estabelece com a cidade. Submetida a críticas, mas também a elogios, o Santuário procura marcar a dependência que a cidade de Aparecida tem de sua instituição. Deixa revelar que sabe que tem papel importante na economia local, bem como na organização da população. Por isso, atua de modo vigilante, fomentando espaços para diálogo e consultado a população sobre os destinos da cidade, abrindo lugar para os moradores falarem, seja nos debates ou encomendando pesquisa de opinião, para saber com que os aparecidenses pensam em relação ao processo eleitoral. No entanto, também não abre mão de tutelar o que será discutido, trazendo seus clérigos mais notórios para marcar posição em relação a determinadas questões de interesse da instituição ou promovendo discussões sobre a cidade nos seus programas diários. Essa presença pública do Santuário, mesmo que seja reconhecida sua importância na dinamização da cidade temporal, não se faz sem tensões. A divulgação da pesquisa de intenção de voto e sua conformação como pauta do dia na cidade mostra isso. Essas tensões são escancaradas nas eleições, mostrando como as fronteiras entre Santuário e cidade são porosas.

Essa atuação do Santuário mostra como a "religião" e o "público" são tomados e entendidos ao longo do processo em que ambos se confrontam, processo que está na base do que Montero, Silva e Sales (2018) consideraram como sendo parte das (re) configurações do secularismo brasileiro. Nesse sentido, as expressões e formas religiosas postas em cena, por meio de estéticas, sensações e materialidades, mudam a maneira como a própria religião é feita, mudança que fica em função das mise-en-scène que são apresentadas nas diferentes arenas em que está situada. Desse modo, conforme sugerem os autores, em diálogo com a abordagem de Beyer (1998), a produção do religioso não tem sua definição dada institucionalmente de antemão, uma vez que a compreensão de sua emergência como experiência pública acaba por fazer parte do problema geral de sua articulação com outros sistemas funcionais, que, no caso em análise, estaria na participação (in)direta nas eleições municipais.

\footnotetext{
10 Turner e Turner (1978) já apontavam para um alargamento das funções dos santuários católicos para além da religião, impactando no crescimento de cidades, nos sistemas de mercado, na construção de estradas e na dinamização da economia e da política.
} 


\section{Referências}

ABÉLÈS, M. Rituel et communication politique modern. Hermés (ISCC/CNRS), [s.l.], n. 4, p. 127-141, 1989.

AGNEW, J. Mapping politics: how context counts in electoral geography. Political Geography, [s.l.], v. 2, n. 15, p. 129-146, 1998.

BALANDIER, G. O poder em cena. Brasília, DF: Editora Universidade de Brasília, 1982.

BARREIRA, C.; PALMEIRA, M. (org.). Política no Brasil: visões de antropólogos. Rio de Janeiro: Ed. Relume-Dumará, 2006.

BARREIRA, Irly; PALMEIRA, Moacir (org.). Candidatos e Candidaturas: enredos de campanha eleitoral no Brasil. São Paulo: Annablume, 2009.

BARREIRA, I. Chuva de papéis. Rio de Janeiro: Relume-Dumará, 1998.

BEYER, P. A privatização e a influência pública da religião na sociedade global. In: STONE, M. F. (org. ). Cultura global: nacionalismo, globalização e modernidade. Petrópolis: Vozes, 1998. p. 395-419.

BRUSTOLONI, J. História de Nossa Senhora da Conceição Aparecida: a imagem, o santuário e as romarias. Aparecida: Editora Santuário, 1998.

CORADINI, O. Origens Sociais, mediação e processo eleitoral num município de imigração italiana. In: BARREIRA, I.; PALMEIRA, M. (org.). Candidatos e Candidaturas: enredos de campanha eleitoral no Brasil. São Paulo: Annablume, 2009. p. 81-104.

FRANÇA, M. C. Pequenos centros paulistas de função religiosa. 1975. 142f. Tese (Doutorado) - Universidade de São Paulo, São Paulo, 1975.

GODOY, A. S. Aparecida: espaços, imagens e sentidos. 2015. 161f. Dissertação (Mestrado) Universidade Estadual de Campinas, São Paulo, 2015.

GODOY, Adriano Santos. "O Papa é o melhor prefeito que a cidade já teve": uma etnografia da paisagem urbana na capital da fé. Religião \& Sociedade, [s.l.], v. 37, n. 2, p. 38-63, 2017.

GOLDMAN, M. Como funciona a democracia: uma teoria etnográfica da política. Rio de Janeiro: 7 Letras, 2006.

GOLDMAN, M.; PALMEIRA, M. (org.). Antropologia, voto e representação política. Rio de Janeiro: Contra Capa, 1996.

HEREDIA, B.; TEIXEIRA, C.; BARREIRA, I. (org.). Como se fazem eleições no Brasil. Rio de Janeiro: Ed. Relume-Dumará, 2002.

HERZFELD, M. Cultural intimacy: Social poetics in the nation-state. New York/London: Routledge, 2014.

MONTERO, P.; BRUM, A.; QUINTANILHA, R. Ritos católicos e ritos civis: a configuração da fala pública da Igreja Católica em dois atos em memória de Vladimir Herzog (1975/2015). Mana, Rio de Janeiro, v. 22, n. 3, p. 705-735, 2016.

MONTERO, Paula; SILVA, Aramis Luis; SALES, Lilian. Fazer religião em público: encenações religiosas e influência pública. Horizontes Antropológicos, [s.l.], n. 52, p. 131-164, 2018.

PALEY, J. (ed.). Democracy: anthropological approaches. Santa Fé: School for Advanced Research, 2008.

PALMEIRA, M. Os comícios e a política de facções. Anuário Antropológico, [s.l.], n. 94, p. 31-94, 1995.

PAlMEIRA, M.; HEREDIA, B. Política Ambígua. Rio de Janeiro: Relume-Dumará, 2010. 
PROCÓPIO, C. E. P. A produção ritual da candidatura política. Cadernos de Campo, [s.l.], v. 23, n. 23, p. $91-108,2014$.

SANCHIS, P. Desencanto e formas contemporâneas do religioso, Ciencias Sociales y Religion, Porto Alegre, ano 3, 2001.

TURNER, Victor. The Center out There: Pilgrim's Goal. History of Religions, University of Chicago, v. 12, n. 3, p. 191-230, 1973.

TURNER, V.; TURNER, E. Image and pilgrimage in Christian culture. New York: Columbia University Press, 1978.

\section{Carlos Eduardo Pinto Procópio}

Professor de antropologia e sociologia no Instituto Federal de São Paulo. É pesquisador-colaborador no Centro Brasileiro de Análise e Planejamento (CEBRAP). Coordena o Grupo de Pesquisa Território, Fronteira e Socialidades (IFSP). Atualmente pesquisa as interfaces entre catolicismo e espaço público. Endereço profissional: Rua Pedro Vicente, n. 625, Canindé, São Paulo, SP. CEP: 01109-010.

E-mail: procopiocso@yahoo.com.br

ORCID: https://orcid.org/0000-0002-6442-3833

\section{Ana Keila Mosca Pinezi}

Professora Associada do Departamento de Saúde Coletiva (DESCO) da Universidade Federal do Triângulo Mineiro (UFTM), é atualmente Visiting-Scholar no Behner Stiefel Center for Brazilian Studies ( San Diego State University (SDSU) - Califórnia, USA). Pesquisa temas como Religião, Pentecostalismos e Protestantismos; Saúde e Religião; Políticas Públicas em Educação e Ações Afirmativas. Coordena o Grupo de Pesquisa IPLURES - "Identidades Plurais e Representações Simbólicas".

Endereço profissional: Departamento de Saúde Coletiva DESCO, Av. Getúlio Guaritá, n. 159, Centro Educacional Abadia, Uberaba, MG. CEP: 38025-440.

E-mail: keipinezi@gmail.com

ORCID: https://orcid.org/0000-0001-9190-7246

\section{Gilson Nascimento de Oliveira}

Licenciado em Geografia pelo Instituto Federal de São Paulo (IFSP). Foi bolsista do Programa Institucional de Bolsas de Iniciação Científica e Tecnológica do Instituto Federal de Educação Ciência e Tecnologia de São Paulo (PIBIFSP) entre 2015 e 2019. Pesquisador do Grupo de Pesquisa Território, Fronteira e Socialidades (IFSP).

Endereço profissional: Rua Pedro Vicente, n. 625, Canindé, São Paulo, SP. CEP: 01109-010.

E-mail: gilsonnasc27@gmail.com

ORCID: https://orcid.org/0000-0001-6113-1870

\section{Como referenciar este artigo:}

PROCÓPIO, Carlos Eduardo Pinto; PINEZI Ana Keila Mosca; OLIVEIRA, Gilson Nascimento de. Política na Capela: eleição municipal no Vale do Paraíba Paulista. Ilha - Revista de Antropologia, Florianópolis, v. 23, n. 3, p. 41-60, setembro de 2021. 